\title{
JOGOS DIDÁTICOS NO CONTEXTO FORMATIVO DE PROFESSORES
}

\author{
Carol Severo; ; Aline Grohe Schirmer Pigatto ${ }^{2}$
}

\section{RESUMO}

O presente trabalho tem como objetivo apresentar um "recorte" dos resultados provenientes da revisão de literatura desenvolvida em nosso projeto de pesquisa, o qual aborda a temática de jogos didáticos no contexto formativo. Por meio da revisão de literatura, delimitada numa busca acerca dessa temática, dentro do Ensino de Ciências da Natureza, visamos conhecer as atuais condições dos jogos. A partir desse recorte, verificamos que muitos professores desconhecem as potencialidades dos jogos e, por diferentes motivos, acabam não utilizando essa ferramenta. Assim, os processos formativos, tanto da formação inicial, quanto da continuada, oferecem suporte que ajudam a superar tais desafios, favorecendo a apropriação e atualização docente perante esse recurso didático.

Palavras-chave: Ensino de Ciências da Natureza; Formação continuada; Formação inicial; Revisão de literatura.

Eixo Temático: Educação, Cultura e Comunicação.

\section{INTRODUÇÃO}

Dentre as diferentes possibilidades didáticas que podem ser adotadas nas aulas da área do Ensino de Ciências da Natureza, o jogo didático se apresenta uma alternativa bastante interessante, utilizada, muitas vezes, para perpassar o caráter tradicional das aulas, tornando as mesmas mais dinâmicas (HORA; LOJA; PIRES, 2018; SOUZA et al., 2020). Assim, a busca por inovações nesse contexto pretende superar as dificuldades, de forma que favoreça a aprendizagem dos alunos.

Quando se trata da superação das dificuldades, o jogo pode configurar-se um facilitador do processo de ensino e aprendizagem, na medida que motiva e desperta a curiosidade dos alunos, tendo o aparato lúdico como um dos principais atrativos,

\footnotetext{
${ }^{1}$ Mestranda no Programa de Pós-Graduação em Ensino de Ciências e Matemática (PPGECIMAT) da Universidade Franciscana (UFN). E-mail: carol.severo@ufn.edu.br

2 Docente da Universidade Franciscana (UFN). E-mail: alinepi@prof.ufn.edu.br
} 
pois, é capaz de proporcionar uma aprendizagem mais prazerosa (MELO et al., 2016; VENTURA; MOREIRA; MOULIN, 2016; COLOMBO, 2019). Dessa forma, o estudo de conteúdos considerados complexos e abstratos ocorre de maneira descontraída, facilitando a aquisição do conhecimento científico (HORA; LOJA; PIRES, 2018; COLOMBO, 2019, SILVA et al., 2019).

Além de motivar a turma, momentos de interação entre alunos e professor são favorecidos por meio do uso de jogos, permitindo a comunicação e a troca de ideias (SILVA et al., 2019). Logo, o trabalho em equipe acaba envolvendo as questões emocionais, principalmente, ligadas aos sentimentos provenientes da vitória, ou, da derrota. Ao encontro disso, os alunos podem tomar a derrota como ponto de partida para que possam aprender com os erros cometidos, buscando superar juntos os desafios do jogo (SCHWARZ, 2006; ADAMS; ALVES; NUNES; 2018; HORA; LOJA; PIRES, 2018).

No entanto, para que o uso dos jogos didáticos seja positivo e contribua para a aprendizagem dos alunos é necessário que o docente se aproprie, de forma coerente, desses recursos. Nesse sentido, o presente trabalho tem como objetivo apresentar um "recorte" dos resultados provenientes da revisão de literatura desenvolvida em nosso projeto de pesquisa, o qual aborda a temática de jogos didáticos no contexto formativo.

\section{METODOLOGIA}

Considerando a temática da nossa pesquisa, voltada aos jogos didáticos, a qual está em desenvolvimento pelo Programa de Pós-Graduação em Ensino de Ciências e Matemática (PPGECIMAT) da Universidade Franciscana (UFN), nos propomos conhecer as atuais condições desses recursos na área Ensino de Ciência da Natureza. Para tal, realizamos uma revisão de literatura da qual enfatizamos aqui um recorte. Assim, vale destacar que o recorte diz respeito apenas a uma parcela da revisão realizada, ou seja, apresentaremos aqui alguns dos trabalhos analisados, pertencentes a uma das categorias criadas, relacionada ao contexto formativo de professores. 
Nesse sentido, destacamos que a revisão de literatura permite uma visão geral acerca da temática pesquisada, favorecendo a atualização e a compactação dos conhecimentos já existentes (FIGUEIREDO, 1990). Corroborando com essas afirmações, Noronha e Ferreira (2000, p. 181-82) destacam que os trabalhos de revisão de literatura são importantes pois:

[...] analisam a produção bibliográfica em determinada área temática, [...] fornecendo uma visão geral ou um relatório do estado da-arte sobre um tópico específico, evidenciando novas idéias, métodos, subtemas que têm recebido maior ou menor ênfase na literatura selecionada. Assim, a consulta a um trabalho de revisão propicia ao pesquisador tomar conhecimento, em uma única fonte, do que ocorreu ou está ocorrendo periodicamente no campo estudado, podendo substituir a consulta a uma série de outros trabalhos. As revisões podem também contribuir com sugestões de idéias para o desenvolvimento de novos projetos de pesquisa.

À vista disso, para tornar clara as etapas percorridas na revisão de literatura, até a apresentação do recorte atribuído ao presente trabalho, iremos descrever os principais procedimentos realizados, concebendo assim, uma maior credibilidade aos mesmos e ao trabalho como um todo.

As buscas foram realizadas no Portal de Periódicos da CAPES, devido ser uma biblioteca virtual de acervo científico que agrega cerca de 130 bases de dados diferentes (CAPES, 2014), entre os dias 21 e 22 de abril de 2021, nos quais foram resgatados 111 trabalhos, idem em ambas as datas. Para a busca, utilizamos o termo (palavra-chave) "jogos didáticos", sendo esse descrito somente em português, com o qual esperávamos deter um alcance considerável em relação a temática da pesquisa.

Após a recuperação de 111 documentos, aplicamos os critérios iniciais de inclusão e exclusão a partir da leitura do título, resumo, introdução, ou, eventualmente, do trabalho na íntegra, devida a impossibilidade de aplicação somente com a leitura dos primeiros citados. Ao adotarmos uma abrangência, delimitamos nosso interesse somente em estudos vinculados a área do Ensino de Ciências da Natureza, sem restrições ao período de publicação. Logo, o critério de inclusão vinculou-se com a abordagem dos jogos dentro do Ensino de Ciências, Biologia, Química ou Física. Por outro lado, o critério de exclusão, vinculou-se com a abordagem de jogos fora dessa abrangência. 
Dessa forma, na primeira filtragem, 78 trabalhos foram inclusos por apresentarem estudos relacionados aos jogos no Ensino de Ciências, Biologia, Química ou Física. Já o processo eliminatório, resultou em um total de 33 materiais exclusos, perante ao fato desses apresentarem estudos com jogos em outras áreas. A partir disso, realizamos a leitura na íntegra dos 78 trabalhos inclusos, de forma atenta, em conjunto com o registro de informações relevantes de cada um deles para otimizar nossas análises.

Por meio dessa leitura integral, os trabalhos foram "categorizados" a partir de três itens, sendo eles: a) Relevância do trabalho para a pesquisa (baixa, razoável, boa, ótima); b) Área específica (Biologia, Ciências, Química ou Física); c) Contexto (o trabalho envolve ensino e aprendizagem, ou, formação de professores). Nesse instante, sinalizamos que o recorte, a qual nos referimos, diz respeito a categoria "c", especificamente, aos trabalhos que envolvem a formação de professores. Logo, para esse quesito acatamos os trabalhos que envolvem as ações com jogos nessa esfera, sendo eles: programas de iniciação à docência, aplicação/testagem de jogos em turmas de graduação, ou, execução desse tipo de recurso em oficinas formativas. Dessa forma, obtivemos um total de 22 estudos nesse quesito. Por outro lado, a partir da categoria "a" realizamos uma nova filtragem, reduzindo nosso corpus de análise de 78 para 60 trabalhos revisados.

Portanto, na próxima seção, apresentaremos as diferentes perspectivas sobre os jogos didáticos presentes nos 22 trabalhos selecionados ${ }^{3}$, possibilitando assim, uma breve visão acerca do que vem sendo trabalhado sobre esses recursos no contexto formativo dentro da área do Ensino da Ciências da Natureza.

\section{RESULTADOS E DISCUSSÕES}

Após sua formação inicial, é relevante aos professores continuarem despertando o desejo de aprender, o que torna cada vez mais relevante a promoção de formações continuadas que possam resgatar sua motivação (ANDRADE; DIAS, 2020; BRITO et al., 2012). Para isso, os jogos didáticos vêm a ser uma interessante

\footnotetext{
3 Toda a introdução do presente trabalho faz parte desse recorte de revisão de literatura. Logo, atribuímos ao início do trabalho algumas das principais concepções mais próprias sobre os jogos, direcionando a próxima seção apenas os aspectos referentes ao contexto formativo.
} 
opção, os quais contribuem para a mobilização, renovação e atualização desses sujeitos, podendo também serem utilizados para ensiná-los durante a graduação, associado ao sentido de que existem diversas formas de se transpor os conteúdos ao alunado (COELHO, 1994; ARAÚJO; AMORIM, 2014; EVARISTO; FARIAS; ALMEIDA, 2020). Como qualquer outra ação didática, é necessário que o professor aprenda a selecionar o jogo em função dos objetivos que se quer alcançar, usando-o com planejamento e cuidados (BRITO et al., 2012; PINHEIRO et al., 2015; ADAMS; ALVES; NUNES; 2018), evitando a causa, ou, fortalecimento de problemas de aprendizagem, até mesmo de atitudes nos alunos, especialmente, vinculados à competitividade e agitação excessiva favorecida ao jogar (SCHWARZ, 2006).

Alguns professores desconhecem as possibilidades dos jogos para 0 processo de ensino e aprendizagem, devido as deficiências inerentes a qualquer processo de formação, o que leva a necessidade de aperfeiçoamento da própria prática, para buscar a ampliação de suas metodologias e estratégias de ensino (ARAÚJO; AMORIM, 2014; MIRANDA; GONZAGA; COSTA, 2016; REIS; MARQUES; DUARTE, 2020). Vamos abrir um breve parêntese nesse instante, pois, em nossa revisão de literatura, percebemos existentes ramificações na formação inicial, que procuram fortalecer tais aspectos, como por exemplo, a atuação antecipada no âmbito do Programa Institucional de Bolsas de Iniciação à Docência (PIBID). Inferimos que dentre os 60 trabalhos analisados, 13 (22\%) deles envolviam, principalmente, ações com jogos desenvolvidas por bolsistas do PIBID. Um número significativo que nos chamou atenção, pois, aponta uma determinada persistência e interesse em relação ao uso desses recursos por alunos no início da trajetória docente. Programas como esse são um diferencial positivo, pois, enquanto os alunos estão em processo de formação, também estão inseridos em instituições públicas de ensino, adentrando a sala de aula e conhecendo seu futuro espaço de atuação, ao mesmo tempo que colocam em prática os conceitos e perspectivas já aprendidos (ANDRADE; DIAS, 2020; BRITO et al., 2012). Nesse sentido, o contato com os jogos, nessa ramificação da formação inicial, fomenta a exploração desse tipo de recurso, estimulando a criação de inovações e o aperfeiçoamento da prática 
pedagógica, promovendo melhorias nesses dois segmentos (BRITO et al., 2012; ADAMS; ALVES; NUNES; 2018).

Por isso, é de extrema importância que tanto licenciandos, quanto professores em cursos de atualização, vivenciem diferentes experiências com esses tipos de recursos, para que assim, consigam mobilizar a curiosidade, a criatividade e o desejo de aprender em seus alunos (REIS; MARQUES; DUARTE, 2020; SCHWARZ, 2006). Esse contato, seja por meio da confecção, ou, a partir da jogabilidade, permite tais sujeitos desenvolver e conhecer suas possibilidades para que possam usá-las para beneficiar a aprendizagem de seus estudantes (BRITO et al., 2012). Ou seja, é pertinente conhecer as características mais relevantes dos jogos para colocálas em ação, o que requer um determinado esforço e interesse (SCHWARZ, 2006).

Nesse sentido, muitos docentes, frente às diversas exigências e as condições de trabalho do seu espaço de atuação, acabam desenvolvendo uma postura de acomodação, a qual prejudica sua adaptação diante aos desafios que surgem no cotidiano da sala de aula. A resistência em consequência das crenças equivocadas acerca dos jogos, como por exemplo meramente decorativos de informações, desqualificam sua aplicabilidade como recurso didático, acarretando dúvidas para com suas contribuições na aprendizagem (SCHWARZ, 2006). Dentre os empecilhos citados para sua utilização, deparamo-nos com o fator tempo como um ponto de destaque, seguido da preocupação em cumprir o conteúdo programado. A carga horária reduzida das disciplinas prejudica a aplicabilidade, pois não é possível concluir todas as etapas que envolvem o jogo (MIRANDA; GONZAGA; COSTA, 2016). O tempo de planejamento também aparece como obstáculo, na medida que a confecção dessa ferramenta requer um momento especial de criação pelo professor. Como uma das estratégias de enfraquecer essa barreira, alguns estudos mostram que é possível a produção de jogos de maneira rápida e simples com materiais acessíveis de baixíssimo custo, os quais podem ser adaptados/readaptados de acordo com a temática que pretendem abranger (BRITO et al., 2012; ANJOS; GUIMARÃES, 2017; MIRANDA; GONZAGA, PEREIRA, 2018). 


\section{CONCLUSÃO}

Apesar dos jogos didáticos se configurarem instrumentos capazes de otimizar o processo de ensino e aprendizagem na área do Ensino de Ciências da Natureza, os professores ainda encontram muitas dificuldades para a sua aplicação em sala de aula. Nesse sentido, o espaço de atuação docente se depara, principalmente, com a falta de tempo para explorar e conhecer esse tipo de recurso, pois, é necessário um bom planejamento para que seu objetivo seja alcançado. No entanto, desafios como esses podem ser superados a partir da participação em oficinas de formação continuada que envolvam a atualização da prática docente.

Antes mesmo de se apropriar dos jogos nesse contexto formativo, os futuros professores podem entrar em contado com tal ferramenta durante sua formação inicial. Esse contato é variante, seja a partir do estudo nos componentes curriculares, seja por meio da participação de programas que permitam a exploração de práticas, como por exemplo o PIBID. Dessa forma, é possível que os futuros docentes conheçam as potencialidades dos jogos didáticos para o ensino, favorecendo sua ação em sala de aula e a aprendizagem dos alunos.

\section{AGRADECIMENTOS}

Na condição de bolsista da Coordenação de Aperfeiçoamento de Pessoal de Nível Superior (CAPES), agradeço a mesma pelo auxílio, por meio da bolsa PROSUC CAPES. Dessa forma, sou muito grata pela oportunidade de poder realizar um mestrado acadêmico no Programa de Pós-graduação em Ensino de Ciências e Matemática (PPGECiMat) da Universidade Franciscana (UFN).

\section{REFERÊNCIAS}

ADAMS, Fernanda Welter; ALVES, Scarlet Dandara Borges; NUNES, Simara Maria Tavares. Gincana da cinética química: superando desafios no processo de ensino e aprendizagem de conceitos químicos. Revista Eletrônica Ludus Scientiae (RELuS). V. 2, 2018. Disponível em: https://revistas.unila.edu.br/relus/article/view/1054/1276. Acesso em: 15/09/2021

ANJOS, José Ayron Lira Dos; GUIMARÃES, Ricardo Lima. Elaboração e validação do jogo do palito no ensino de nomenclatura de compostos orgânicos. Revista 
Eletrônica Ludus Scientiae (RELuS). V. 1, 2017. Disponível em: https://revistas.unila.edu.br/relus/article/view/741/727. Acesso em: 15/09/2021

ARAÚJO, Magnólia Fernandes Florêncio de; AMORIM, Aline de Souza. Percepções de professores sobre o uso de atividades lúdicas para tratar o tema "água e saúde" em ações de educação ambiental numa região semiárida. HOLOS. V. 6, 2014. Disponível em: https://core.ac.uk/download/pdf/208409465.pdf. Acesso em: $15 / 09 / 2021$

BRITO, Lya Christina Da Costa et al. Avaliação de um minicurso sobre o uso de jogos no ensino. Revista Brasileira de Pós-Graduação. Pibid: experiências e reflexões. V. 8. Brasília: 2012. Disponível em:

http://ojs.rbpg.capes.gov.br/index.php/rbpg/article/view/257/246. Acesso em: 15/09/2021

COELHO, Marília Martins. Sala de Aula de 3ำ Grau: Constituindo Jogos Didáticos para o Ensino de Ciências na Escola de Primeiro Grau. EDUCAÇÃO: Teoria e Prática. V.2, 1994. Disponível em:

https://www.periodicos.rc.biblioteca.unesp.br/index.php/educacao/article/view/2416/2 142. Acesso em: 15/09/2021

COLOMBO, Daniel Augusto. Jogos Didáticos como Instrumentos de Ensino. Revista Insignare Scientia. V. 2, 2019. Disponível em:

https://periodicos.uffs.edu.br/index.php/RIS/article/view/11184/7252. Acesso em: 15/09/2021

Coordenação de Aperfeiçoamento de Pessoal de Nível Superior (CAPES). Guia de uso do Portal de Periódicos da CAPES. Ministério da Educação (MEC), 2014.

EVARISTO, Gabriel Filipe; FARIAS, Christian Roberto de; ALMEIDA, Vitor Luiz Campese Gonçalves de. Assessing the educational game "The Wall Chemistry Game" potential for kinetics chemistry teaching. ACTIO: Docência em Ciências. V.5, Curitiba: 2020. Disponível em: http://oaji.net/articles/2020/6441-1588356976.pdf. Acesso em: 15/09/2021

FIGUEIREDO, Nice. Da importância dos artigos de revisão da literatura. Revista Brasileira de Biblioteconomia e Documentação. V. 23, São Paulo: 1990.

HORA, Maeli Rodrigues de Oliveira Paiva da; LOJA, Luiz Fernando Batista; PIRES, Diego Arantes Teixeira. JOGO DO CÉSIO: UTILIZANDO JOGOS DIDÁTICOS PARA O ENSINO DE CÁLCULOS ESTEQUIOMÉTRICOS. Revista Eletrônica Ludus Scientiae (RELuS). V. 2, 2018. Disponível em: https://revistas.unila.edu.br/relus/article/view/917/1252. Acesso em: 15/09/2021

MELO, Alessandra Cunha et al. JOGOS DIDÁTICOS NO ENSINO DE QUÍMICA. Revista Eletrônica Ambiente. V. 8, 2016. Disponível em: https://periodicos.uerr.edu.br/index.php/ambiente/article/view/246. Acesso em: 15/09/2021 
MIRANDA, Jean Carlos; GONZAGA, Glaucia Ribeiro; COSTA, Rosa Cristina. Produção e avaliação do jogo didático "tapa zoo" como ferramenta para o estudo de zoologia por alunos do ensino fundamental. HOLOS. V. 4, 2016. Disponível em: http://www2.ifrn.edu.br/ojs/index.php/HOLOS/article/view/4100/1539. Acesso em: $15 / 09 / 2021$

MIRANDA, Jean Carlos; GONZAGA, Glaucia Ribeiro; PEREIRA, Patrícia Elias. Abordagem do tema doenças sexualmente transmissíveis, no ensino fundamental regular, a partir de um jogo didático. ACTA: Biomedica Brasiliensia. V. 9, 2018. Disponível em:

https://www.actabiomedica.com.br/index.php/acta/article/view/286/192. Acesso em: $15 / 09 / 2021$

NORONHA, Daisy Pires; FERREIRA, Sueli Mara. Revisões de literatura. Fontes de informação para pesquisadores e profissionais. Belo Horizonte: UFMG, 2000.

PINHEIRO, Iraciana Antônia de Morais et al. Elementum - lúdico como ferramenta facilitadora do processo de ensino-aprendizagem sobre tabela periódica. HOLOS. V. 8, 2015. Disponível em:

http://www2.ifrn.edu.br/ojs/index.php/HOLOS/article/view/3647/1312. Acesso em: $15 / 09 / 2021$

REIS, Jáina Araújo; MARQUES, Renata Martins; DUARTE, Enios Carlos. Análise da produção argumentativa com uso de jogo didático investigativo em uma aula de Biologia. Revista de Ensino de Ciências e Matemática. v. 11, São Paulo: 2020. Disponível em: http://revistapos.cruzeirodosul.edu.br/index.php/rencima/article/view/1725/1402. Acesso em: 15/09/2021

SCHWARZ, Vera Regina Karpss. CONTRIBUIÇÃO DOS JOGOS EDUCATIVOS NA QUALIFICAÇÃO DO TRABALHO DOCENTE. Porto Alegre: 2006. Disponível em: https://repositorio.pucrs.br/dspace/bitstream/10923/3052/1/000383790Texto\%2bCompleto-0.pdf. Acesso em: 15/09/2021

SILVA, Isabela Vieira da, et al. DESENVOLVIMENTO DE JOGOS DIDÁTICOS AUXILIARES EM PRÁTICAS TRANSDISCIPLINARES E DA ALFABETIZAÇÃO CIENTÍFICA NO ENSINO DAS CIÊNCIAS DA NATUREZA. Revista Insignare Scientia. V. 2, 2019. Disponível em:

https://periodicos.uffs.edu.br/index.php/RIS/article/view/10959/7334. Acesso em: $15 / 09 / 2021$

SILVA, Nathalya Marillya de Andrade; DIAS, Márcia Adelino Da Silva. O uso do jogo de tabuleiro na construção da aprendizagem dos conteúdos de biologia: uma pesquisa desenvolvida no âmbito do PIBID/UEP. Revista Brasileira de Ensino de Ciências e Tecnologia. V. 13, Ponta Grossa: 2020. Disponível em: https://periodicos.utfpr.edu.br/rbect/article/view/7996/pdf. Acesso em: 15/09/2021 
SOUZA, Joyce Soares de et al. Os jogos didáticos e a aprendizagem em Química: uma visão dos professores supervisores do PIBID. Research, Society and Development. v. 9, 2020. Disponível em:

https://rsdjournal.org/index.php/rsd/article/view/7868/6931. Acesso em: 15/09/2021

VENTURA, Juliana Pacheco; RAMANHOLE, Sílvia Kátia de Souza; MOULIN, Monique Moreira. A IMPORTÂNCIA DO USO DE JOGOS DIDÁTICOS COMO MÉTODO FACILITADOR DE APRENDIZAGEM. Revista Univap, 2016. Disponível em: http://www.inicepg.univap.br/cd/INIC 2016/anais/arquivos/0739 1418 01.pdf Acesso em: 15/09/2021 